The author expressed his indebtedness to all his colleagues, to Prof. Geikie, to the Hydrographer and officers of the hydrographic department, and in a special manner to Sir Wyville Thomson, under whose direction and advice all the observations had been conducted.

Challenger Office, 32, Queen Street, Edinburgh.

\section{THE JAMIN CANDLE}

A NEW system in addition to those already prominent in the extensive field of electric lighting is shortly to be introduced into this country in the form of a candle devised by the well-known French electrician M. Jamin. This invention brings with it a considerable reputation, and how far this may be justified we shall probably soon have the opportunity of judging.

It has not yet had a trial in England, and until this is done we can only rely on the results of experiments, apparently of a not very exhaustive or conclusive character, which have taken place in Paris, and which must be accepted with a considerable amount of reservation.

The following description of the new candle is that given by M. Jamin himself in his paper to the French Academy of May 3I, 1880:-

"I have had the honour to submit to the Academy during its sitting of March I7, 1879, the principle of a new electric burner.

"I have since succeeded in constructing a practical Iamp, which I will describe. It rests on a slate base, which can be fixed into the globes or lanterns, according to the requirements of the decorations, and which supports at the base a gutter of copper, wide, but not very thick, in order to avoid shadows, and at the top is a gutter of soft iron, intended to be magnetised and to attract a movable armature or plate. The alternating current of a Gramme machine passes first through a wire of thin copper folded round the gutter some fifteen or twenty times, and which constitutes the directing circuit. In the middle of this frame and in the same plane are placed the candles or pairs of carbon rods between which the electric arc is to play. There are three, but a larger number can be inserted if the lighting is to be prolonged. Each carbon rod is inserted in a metal socket, in which they stand vertically, point downwards, and are retained in this position by means of a spring.

"The working offers no difficulties and demands no skill. There is no insulating material between the carbons. Those on the right are fixed and vertical ; those on the left, hang freely from hinges; the tops of their supports are conected by a small bar, which gives them a movement in common; the armature is attached by a lever to this bar, which it pushes towards the left by its weight, which brings the carbons together until one of them touches its companion. It is to be remarked that the contact will only be made in one of the candles, the longest, or the one whose points hang nearest together; that one will be lighted.

"The electric current, after having traversed the directing circuit, arrives simultaneously at the movable carbons, and can return indiscriminately by the three fixed carbons; it passes between those which touch, and lights them. Immediately the magnetism is made the armature is attracted, the three couples of carbons spring apart at the same time, two remaining cold, and the arc being established in the third. As long as there is any matter to burn it continues maintained at the points by the action of the directing current, and necessarily returning to it if any foreign cause should drive it away. When the current stops the armature falls back, and the contact is re-established ; if it passes through again, the carbons are relighted, and spring apart as at first. Thus the lighting is automatic, instantaneous, and renewable'at will.

"When the first candle is consumed, another must succeed it. For this purpose the left carbon-holder, which remained fixed, is jointed at the top and can be displaced, not in the plane of the frame, but perpendicularly. It is pushed by a spring, $R$, which tends to force it away, but it is kept vertical by a wire, $\mathrm{B}$, bent round like a hook at its end, and which slides tightly in a receptacle where a spring presses it. When the combustion of the candle has brought the arc up to this point, the wire is melted, the carbon-holder is released, the two carbons spring suddenly apart, and the arc is extinguished, but immediately relights in the neighbouring candle. The change is so rapid that the action is hardly perceptible, and the other lamps in the same circuit are not at all affected.

"Besides, it must be remarked that this substitution of a fresh candle for the one consumed only happens every two hours, that the wire is only melted at its extremity, that it is sufficient to cut off the point to bend it again and to draw it a little further from its receptacle, when new carbons are to be inserted, and that it serves for a great number of times. One of the greatest incon. veniences of electric lighting is the possible sudden extinction of one of the lamps, which immediately causes that of the other candles in the same circuit, although they may be in good condition. Ours are very little subject to this danger, but it must, however, be foreseen and remedied. For this purpose one of my pupils has devised a system, the description of which would be too long. Its effect is ( $I$ ) to open, at the moment of accident, a secondary circuit, which continues the current across the faulty candle; (2) to replace the extinguished lamp by an equal resistance, which leaves the others in the condition in which they were at first.

"This addition is very important, as it permits of our lighting many or few candles without changing their brilliancy.

"To sum up, our lamp contains many essential qualities. It lights and relights itself as often as required; it only requires one circuit for all the neighbouring candles; it replaces antomatically those which are entirely consumed, by new carbons; it employs no insulating material which might alter the colour of the flame; and it requires no preliminary preparation of the carbons, which considerably diminishes the expense. If at first it underwent, like all others, variations of brilliancy that were owing, not to the construction, but to the defective preparation of the carbons, these variations have disappeared since, thanks to M. Carré, to whom so much is already due, and who has just given to his carbons the necessary solidity."

In the summer of 1878 the writer, in conjunction with $\mathrm{Mr}$. McEniry, carried out a series of experiments with various forms of electric candles for Mr. Robert Sabine ; the result is embodied in his provisional specification of November 27, 1878, part of which runs as follows :-

"My third improvement in regulating the distance between the carbon electrodes of a regulator or lamp consists in taking advantage of the well-known fact that parallel conductors attract or repel each other according as the currents in them go in the same or in opposite directions. For this purpose I place the carbons vertically side by side, one of them being fixed and the other balanced over a fulcrum or centre. The frames carrying the two carbons form portions of the common electric circuit in such a way that when the current circulates the parallel portions of the balanced frame (which carries the movable carbon) are deflected and the carbons separated. The degree of deflection of the flame depending upon the current, it follows that, should from any cause the electromotive force in the circuit increase, the frame is thereby deflected more, and the electric arc is correspondingly increased in length, which reduces the current again and maintains the light more steadily than when the carbons are placed immovably side by side without any such adjustment."

It is presumed by the writer that M. Jamin's paper to the French Academy of March I7, 1879, explaining the principle of his new candle, was the first public notice of it, and it will be therefore clearly seen that the part of the apparatus which he claims as particularly his own, viz., the directing frame, is in reality due to Mr. Sabine, and that while giving every credit to M. Jamin for independence of thought, it is only in common justice to Mr. Sabine that he should receive the merit of an ide? which, in the words of a very flattering notice of the origin of Jamin's candle in a recent number of La Lumiere Electrique, constitutes an elegant application of Ampère's laws.

Mr. Sabine's arrangement is also of a more simple nature than the candle just described, for it not only regulates the arc but separates the carbons without the aid of magnetism, and this could be as easily accomplished for a combination of three candles as for one.

It is probable that this latter candle was never constructed beyond the experimental stage, but that it could be put into a very simple and practical form is obvious.

Having thus shown that the two systems are identical, we will turn our attention to the consideration of the claims of this particular form of candle as now perfected and brought forward by M. Jamin.

It is questionable whether the surrounding frame of wire is as efficacious as we are led to believe, but that it exerts a certain influence on the electric arc is beyond doubt; but whether this favours the light or acts detrimentally by blowing and expanding the arc remains to be proved. Again, the fact of burning an 
electric candle point downwards cannot be claimed as anything new, for the candles of Mr. Wilde have been successfully used in this position and without any directing frame. This latter, being of fine wire, must offer a considerable resistance to the current, and cannot be overlooked. It is claimed as an advantage in this system that the leading wires used are of the smallest description even for considerable distances, but the same may be said of any other system where the current-producing machine has a very high electromotive force. The size of wire for the circuit is not dependent upon any particular form of candle or regulator, but upon the current-producing strength of the machine employed for working the system.

The automatic lighting and re-lighting of the Jamin candle shows no advance over the means employed by others, nor does the insertion of a resistance in the place of an extinguished lamp constitute anything new. In any construction of candle where the two carbons are separated by the action of magnetism (one carbon being movable and attached to an armature influenced by an electro-magnet) it is impossible to keep the distances of the carbons apart always constant. Any variation in the current produces a corresponding variation in the magnetism which affects the movable carbon, this being especially the case in using alternating currents where the carbon must necessarily be in a continual state of vibration from the rapid changes of polarity.

Those candles of the Jablochkoff type are free from such a fault, owing to both carbons being made quite rigid by the insulating material between them, and the distance apart, therefore, being invariable throughout the whole length, which conduces greatly to the steadiness of the arc.

It is probable that the brilliancy of the light may be increased by burning the candle point downwards, but it must consume more rapidly than when in the reverse position, as the arc would tend to warm the carbon rods throughout their length. It is however certain that improvements will be made, and that probably this system will eventually compete favourably with others already established, although at present it is difficult to see much advantage over such candles as Wilde's, Rapieff's, \&c.

T. E. G.

\section{SOCIETIES ANI ACADEMIES}

\section{Paris}

Academy of Sciences, August 2.-M. Edm. Becquerel in the chair.-The following papers were read:-On the preparation of chlorine, by M. Berthelot. The formation of the brown soluble compound (preceding the liberation of chlorine) requires not only chlorine and manganese, but a considerable excess of hydrochloric acid; it is a perchlorised chlorhydrate of manganese.-On heats of combustion, by M. Berthelot. This relates to the agreement between Thomsen's results and his own.Synthesis of hexamethyl benzine and of mellic acid, by MM. Friedel and Crafts._On human walking, by M. Marey. With his odograph he proves that the step is longer in mounting than in descending for an unburdencd man than for one carrying a load, for one with very low-hecled, than for one with highheeled shoes, for one with a thick sole prolonged slightly beyond the foot than when the sole is short and flexible. It seems as though the heel might be lowered indefinitely with advantage, but soles must not be elongated beyond a certain limit, nor made quite rigid. Sometimes (as in ascending) the length of the step is increased, and the rhythm retarded; at other times (as in nore rapid walking) the step both lengthens and is accelerated.Report on the interoceanic canal project. (Second Part.) M. de Lesseps' documents are approved.-On the gallicolar phylloxera and Phylloxera vastatrix, by M. Laliman.-M. Zazareff described a battery in which electricity is produced by pas* sage of a solution of glycerine, under pressure, through a mixturc of coke and anthracite.-On the theory of sines of superior orders, by M. Farkas.-Researches on the electric effluvium (silent discharge), by MM. Hautefeuille and Chappuis. M. Thenard's apparatus (with alternative discharges) is well fitted to show the rain of electric fire in various gases. Fluoride of silicium gives the best effects ; nitrogen comes next; hydrogen and chlorine also present the phenomenon.-Researches on batteries, by M. D Arsonval. He indicates two methods of obviating the chemical action which goes on in batteries with two liquids when the circuit is open. The first consists in use of animal charcoal, substituted e.g. for the sand in a Minotto battery; the second, in using, as a depolariser, a liquid which gives a precipitate by its mixture with the liquid which attacks the zinc (there are many ways of doing this; and the author mentions some). In the latter case the diaphragm is rendered impermeable by means of a conducting and electrolysable precipitate. - On the optical properties of mixtures of isomorphous salts, by M. Dufet. Let $N$ be the index of the mixed salt, $n$ and $n^{\prime}$ those of the components, $p$ and $p^{\prime}$ the numbers of equivalents of the two salts; then $N=\frac{p n+p^{\prime} n^{\prime}}{p+p^{\prime}}$. This law is demonstrated, at least, for sulphates of the magnesian series.-Influence of temperature on the distribution of salts in their solutions, by $M$. Soret. The concentration of the heated part diminishes, that of the cold increases. The difference grows with the original concentration, and nearly in proportion. In the series of the alkaline chlorides the difference is greater (for the same concentration), the higher the molecular weight of the salt. The phenomenon seems to have no relation to solubility of the salt. - On the rise of the zero point in mercury thermometers, by $\mathrm{M}$. Crafts. This rise (through heating) is quicker and greater in crystal thermometers than in those of glass without oxide of lead; it is quicker at first, and tends to a limit (with heating at fixed temperature). The zero point becomes fixed at the new height, when the instrument is kept at ordinary temperature and the thermometer becomes more stable.-Development, by pressure, of polar electricity, in hemihedral crystals with inclined faces, by MM. Jacques and Curie.-On the pyridic bases, by M. de Coninck.-On the heats of combustion of some substances of the fat-series, by $M$. Louguinine.-Identity of acute experimental septicænia with the cholera of fowls, by M. Toussaint.-Formation of new races; researches in comparative osteology, on a race of domestic oxen observed in Senegambia, by $M$. de Rochebrune. The animal-a zebu-is specially distinguished by a conical nasal horn. - Action of poison on cephalopoda, by M. Yung. The effects of curare, strychnine, nicotine, \&c., are described. - On a hailstorm at Paris on July 30, 1880, by $M$. Ferrière.-On determination of crystallisable sugar in presence of glucose and dextrine, by M. Pellet.

$$
\text { VIENNA }
$$

Imperial Academy of Sciences, July 1.-The following, among other papers, were read:-Development and formation of the glands of the stomach, by Prof. Toldt.-Tuberculosis, by Prof. Heschl. - On the absorption of radiant heat in gases and vapours, by Herr Lecher and Herr Pernter.-On an optical property of the cornea, by Prof. Fleischl.

\section{CONTENTS}

Page

AnCIENT GeOGKAPHY . . . . . . . . . . . . 333

The Menhadrn . . . . . . . . . . . . . . . : 333

OUR BOOK SHEIP:-

Ross's "Alphabetical Manual of Blowpipe Analysis" . . . . 336

Wal's "U.S. Coast and Geodetic Survey " * * * * * 336

Vinter's "Tables for the Analysis of a Simple Salt " . : : : : 337

LETTERS TO THE EDITOR:-

The late Count L. F. de Pourtales.-Prof. P. Martin Duncas,

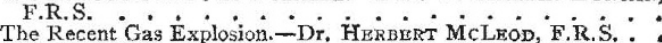

The Recent Gas Explosion.-Dr. HERBERT McLEod, F.R.S. . 337

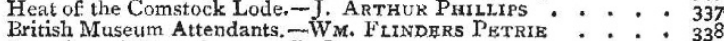

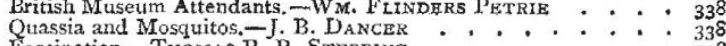

Strange Method of Crossing a Torrent.-Surgeon-Major 'w.

CunRar

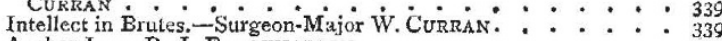

Anchor-Ice.-R. J. FarQUUARSON * . .

Depraved Taste in Animals.-ARTHur Nicols . . . . . . . 339

Thundzrstorms. By Prof. Tait (With Illustration) * * * * 339

Onservations on ARCTIC Tossil Floras With Regard to Tem-

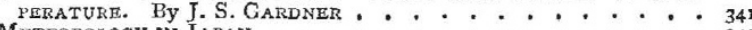

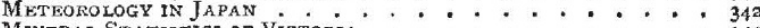

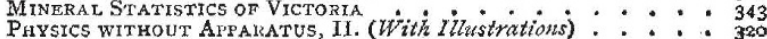

Physics without Appaliatus, II. (With Ihlistrations) : : : : $3^{20}$

NOTES .

UR Astronomical Columi:-

Comets of Short Period

Is $n$ Cygni a Variable

Geology of Belgium and the North of France . . . 348

The Right of Priority in Palæontological Nomenclature . . . 348

Geological Survey of New Jersey . . . . . . . . . . $34^{8}$

Central Asian Geology. 48

Geology of Geneva.

Jurassic Rocks of the Altai Mountains : : : : : : : : : $: 3^{349}$

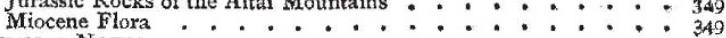

Chemical Noths . . . . . . . . . . . . . . . . . 349

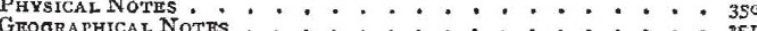

The Structure and Origin of Coral Rebirs and isininds. By.

John Murray ... . . . . . . . . * . 35

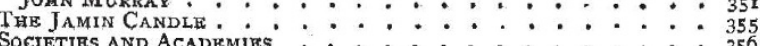

